\title{
Does affect-improving interpersonal affect regulation influence others' task performance? The mediating role of positive mood
}

DOI:

10.1080/1359432X.2019.1666105

\section{Document Version}

Accepted author manuscript

Link to publication record in Manchester Research Explorer

Citation for published version (APA):

Holman, D., \& Niven, K. (2019). Does affect-improving interpersonal affect regulation influence others' task performance? The mediating role of positive mood. European Journal of Work and Organizational Psychology. https://doi.org/10.1080/1359432X.2019.1666105

\section{Published in:}

European Journal of Work and Organizational Psychology

\section{Citing this paper}

Please note that where the full-text provided on Manchester Research Explorer is the Author Accepted Manuscript or Proof version this may differ from the final Published version. If citing, it is advised that you check and use the publisher's definitive version.

\section{General rights}

Copyright and moral rights for the publications made accessible in the Research Explorer are retained by the authors and/or other copyright owners and it is a condition of accessing publications that users recognise and abide by the legal requirements associated with these rights.

\section{Takedown policy}

If you believe that this document breaches copyright please refer to the University of Manchester's Takedown Procedures [http://man.ac.uk/04Y6Bo] or contact uml.scholarlycommunications@manchester.ac.uk providing relevant details, so we can investigate your claim.

\section{OPEN ACCESS}


Holman, D. \& Niven, K. (in press). Does affect-improving interpersonal affect regulation influence others' task performance? The mediating role of positive mood. European Journal of Work and Organisational Psychology.

\title{
Does affect-improving interpersonal affect regulation influence others' task performance? The mediating role of positive mood \\ David Holman \& Karen Niven,
} Alliance Manchester Business School

\begin{abstract}
An important part of many job roles - such as coaches, instructors, and leaders - is trying to improve the performance of others. In this paper we examine whether affect-improving interpersonal affect regulation (i.e., deliberate attempts to improve the emotion and mood of another person) plays a positive role in this process. We develop a model which proposes that the positive relationship between the receipt of interpersonal affect regulation and task performance is mediated by positive mood. Results of two dyadic studies (one with academics and doctoral students, $\mathrm{N}=78$, the other with driving instructors and learner drivers, $\mathrm{N}=100$ ) support the hypothesised model, and show that the effects of interpersonal affect regulation are over and above the effects of emotional contagion. Our findings extend theoretical understanding of the effects of interpersonal affect regulation by illustrating a core mechanism through which it influences others' task behaviour. Our research also provides new evidence on the relational and affective processes through which people holding key organizational roles (e.g., coaches, instructors, mentors, leaders) are able to improve others' task performance.
\end{abstract}

Key words: interpersonal affect regulation, performance, dyadic survey 
Affect is a driving force for employees' performance. Over recent years, it has been established that affective states, and positive moods in particular (i.e., prolonged feelings characterised by pleasant activation or deactivation such as enthusiasm or calmness) can facilitate a range of performance-related behaviours in the workplace (Erez \& Isen, 2002; Rothbard \& Wilk, 2011; Russell \& Barrett, 1999; Seo, Barrett \& Bartunek, 2004; Tsai, Chen \& Lui, 2007). For those in roles such as supervisors, instructors and teachers who are responsible for improving the task performance of others (e.g., team members, clients or students), this implies that strategically improving another person's positive mood may be an important means of improving another person's task performance. One way of improving another person's positive mood is through the use of interpersonal affect regulation, i.e., the deliberate initiation, maintenance or modification of the occurrence, intensity, or duration of affect in others (Niven, Totterdell, \& Holman, 2009) ${ }^{1}$. Indeed, Niven (2016) has proposed that one of the main motivations underlying the use of interpersonal affect regulation (IAR) by organisational actors is to improve the performance of targeted others, e.g., team members or clients. However, when organisational actors direct IAR towards a particular target, it is yet to be established whether the actor's use of IAR influences the target's task performance and whether this occurs through its effects on the target's positive mood. The main aim of this paper is therefore to examine whether IAR facilitates the task performance of others via the mechanism of positive mood. To achieve our aim, we develop a theoretical model drawing on theories relating to the function of IAR, and on the broaden-and-build theory of affect (Fredrickson, 2001), to explain how affect-improving IAR strategies can elicit positive mood in others, and how in turn positive mood can enhance the other person's task performance (See Figure 1). We test the proposed model in two dyadic studies, one involving

\footnotetext{
${ }^{1}$ IAR is different from processes such as the self-regulation of affect or emotional labour, as it concerns regulation of other people's feelings rather than one's own (Gross, 1998; Hochschild, 1983; Niven, 2017).
} 
university academics and doctoral students, the other using driving instructors and learner drivers.

Work on IAR by Niven and colleagues (Niven, Totterdell, Holman, \& Headley, 2012) also suggests that employees are often in a positive mood when they use affect-improving IAR. The co-occurrence of employee IAR and employee positive mood means that the purported effects of an employee's IAR on others may actually result from the employee's positive mood (Parkinson, Fischer, \& Manstead, 2005). In particular, an employee's positive mood may influence others' positive mood through a process known as primitive emotional contagion, which occurs when the mood of one person is unconsciously 'caught' by others (Hatfield, Cacioppo, \& Rapson, 1994). As such, it is important to establish if the effects of an employee's IAR on others occur in addition to those effects that may occur as a result of the employee's positive mood. Our second aim is therefore to test (in Study 2) the joint effects of employee IAR and positive mood on others' positive mood and task performance.

Our paper makes four important contributions to the literature. First, by examining the effects of IAR, we provide new insight into the ways in which task performance can be managed and enhanced within organizational relationships, e.g., between instructors and learners, coaches and clients, leaders and followers. Second, our paper extends the known consequences of IAR. To date, research has demonstrated the effects of IAR on people's well-being and the quality of their relationships (Little, Kluemper, Nelson, \& Ward, 2012; Martinez-Íñigo, Poerio, \& Totterdell, 2013; Niven, Holman \& Totterdell, 2012; Niven, Totterdell, Holman, \& Headley, 2012) and a recent study also suggested that IAR might influence aspects of extra-role performance, such as organizational citizenship behavior, through its influence on leader-membership exchange (Little, Gooty, \& Williams, 2016). However, the research we present here is the first to examine whether IAR actually affects another's task performance, i.e., the extent to which task or in-role requirements are met 
(Griffin, Neal \& Parker, 2007). Third, our paper is the first to examine a core theoretical mechanism through which IAR may affect task performance, namely, positive mood. By establishing whether effects on positive mood are the reason why IAR influences task performance, we therefore enhance understanding of the pathways through which IAR influences outcomes in other people. Fourth, to date, no study has simultaneously tested the joint effects of an employee's IAR and positive mood on others' affect and behaviour. We therefore help to provide a more integrated understanding of the affect-related processes through which employees can shape the mood and task performance of others.

\section{Theoretical Background and Hypothesis Development}

Our model, shown in Figure 1, proposes that the IAR of an actor (e.g., coach, supervisor) will increase the positive mood of the target (e.g., learner, team member), which in turn will improve the target's task performance. As such, there are two key components to the model: the interpersonal effects of the actor's IAR on the target's positive mood; and the intrapersonal effects of the target's positive mood on his or her task performance. We start by explaining the intrapersonal effects of positive mood on task performance.

Positive mood and task performance. Current theories of affect generally assert that core affective experiences are characterised by feelings of pleasure and displeasure, and activation and deactivation (Russell, 2003) and that affective experiences are characterised by moods (i.e., prolonged affective experiences that may not have a direct object) and emotions (e.g., very short affective experiences that have a definite cause, beginning and end). Moods in particular tend to be distinguished according to whether they involve feelings of pleasure or displeasure, and activation or deactivation (Russell, 2003). In this paper we focus on positive mood (i.e., prolonged feelings characterised by pleasant activation or deactivation such as enthusiasm or calmness) because of the theoretical and empirical evidence showing their influence on a range of performance-related behaviours in the workplace (Christian, Garza \& 
Slaughter, 2011; Erez \& Isen, 2002; Lyubomirsky, King \& Diener, 2005; Rothbard \& Wilk, 2011; Seo et al., 2004; Tsai et al., 2007).

The primary theoretical perspective that helps to explain the salient role of affect in workplace performance is Fredrickson's (2001) broaden-and-build theory, which asserts that positive affective states, such as positive mood, can enhance task performance for three key reasons. First, positive affect can broaden the use of existing behavioral repertoires, enabling a person to cope better with task demands (Fredrickson \& Branigan, 2005). For example, a study by Fredrickson and Joiner (2002) found that positive affect was associated with taking wider perspectives on problems and developing multiple solutions. Second, positive affect can broaden attention to a wider array of stimuli, enabling the person to respond quickly to task demands and to obtain task-relevant information. Evidence for the broadening effects of positive affect on attention comes from experimental studies which show that positive affect extends visual search patterns, particularly with regard to peripheral stimuli in the visual field, and also enables individuals to update their mental representations of the environment (Derryberry \& Tucker, 1994; Friedman \& Förster, 2010; Wadlinger \& Isaacowitz, 2006). Third, by facilitating the integration of new and existing knowledge, positive affect can enable a person to build enduring task knowledge that helps performance in the long term. This effect is seen in experimental studies which show that individuals in a positive mood are more likely to combine information into novel and creative ideas (Isen, 2008; Isen, Daubman, \& Nowicki, 1987), as well as field studies which show positive mood to be associated with higher levels of knowledge and skill acquisition during training and educational programs (Colquitt, LePine, \& Noe, 2000; Konradt, Filip, \& Hoffmann, 2003; Martocchio, 1994; Warr \& Downing, 2000). The core implication of broaden-and-build theory, that positive mood influences task performance, is supported by research evidence from work and non-work domains (Lyubomirsky et al., 2005; Miner \& Glomb, 2010; Totterdell, 1999; Totterdell \& 
Holman, 2003; Tsai et al., 2007; Warr, Bindl, Parker and Inceoglo, 2014). We therefore hypothesise:

Hypothesis 1: A person's positive mood is positively related to his or her task performance.

Interpersonal affect regulation and positive mood. The potential effects of positive mood on task performance have important implications for those in roles (e.g., instructors, teachers, leaders) who are responsible for improving the task performance of others. In particular, these effects suggest that strategically managing others' affect through interpersonal affect regulation may be an important means of helping others to improve their task performance (Sutton, Mudrey-Camino, \& Knight, 2009; Towler, Arman, Quesnell, \& Hoffman, 2014) in addition to other cognitive and behavioural performance management strategies, such as goal setting or skill development (Locke \& Latham, 1990).

There are four main theoretical routes through which IAR can enhance the positive mood of others. First, IAR strategies enhance positive mood by helping others to reappraise their situation. For example, if a follower expresses worry about his or her performance, a leader might use IAR to encourage the follower to reappraise perceptions of goal progress, e.g., by praising improvements or achievements (Carver \& Scheier, 1990). Second, IAR strategies can be used to divert others' attention away from a situation to aid the pursuit of a desired mood. For instance, a teacher might get the student to recall past successful episodes, as the recall of successful events can induce positive emotions (Westerman, Spies, Stahl, \& Hesse, 1996). Third, IAR strategies can enhance positive mood by modifying the situation so as to change its affective impact. For example, a driving instructor might take a short break to let the student relax or change a task to one in which goal achievement and positive mood are more likely (Nummenmaa \& Niemi, 2004). Fourth, IAR strategies can be used to communicate a message about the relationship between the regulator and target, which 
should enhance desired feelings. For instance, a mentor might display a caring attitude towards a mentee as a sign of interpersonal liking (Mikulincer \& Shaver, 2009), which is an important property of rewarding social relationships that is associated with positive mood (Ferris et al., 2009; Richards \& Schat, 2011). While some researchers refer to IAR strategies by names reflecting these four key routes (i.e., cognitive reappraisal, attentional deployment, situation modification, relational engagement; Little et al., 2012; Niven et al., 2009), some strategies may improve mood in multiple ways. For example, the strategy of encouraging a student to do a different task in a different place may improve the student's mood by altering the situation and their attentional focus.

These four routes suggest that when a person perceives that someone else is using affectimproving IAR strategies towards them, this will be positively associated with their positive mood. Evidence to support this comes from the study by Niven, Totterdell and Holman (2007) who found that the perceived receipt of affect-improving IAR strategies was associated with higher positive mood. We therefore hypothesise:

Hypothesis 2: Receipt of IAR will be positively associated with positive mood.

We have used theories of IAR and emotion regulation to propose that a person's receipt of affect-improving IAR will increase his or her positive mood, and we have used broadenand-build theory to propose that a person's positive mood will improve his or her task performance. The combination of these theoretical arguments, and associated empirical evidence, suggests a mediated process wherein the perceived receipt of IAR over time (i.e., from teachers, mentors or instructors) will be associated with the prolonged experience of positive mood, which in turn will sustain a raised level of task performance. The mediational process that we propose is consistent with affective events theory, which asserts that affective events in organisations (e.g., the perceived receipt of IAR) are a proximal cause of employee 
affect (i.e., positive mood) which then, in turn, has a significant effect on workplace behaviour such as task performance (Weiss \& Cropanzano, 1996). The proposed mediational process is also consistent with the idea that organisational actors are motivated to used IAR to improve another person's mood in the expectation that this will then improve that person's task performance (Niven, 2016). Based on this, our third hypothesis is:

Hypothesis 3: Positive mood mediates the positive relationship between receipt of IAR and task performance.

Employee positive mood and interpersonal affect regulation Evidence indicates that people who engage in affect-improving IAR may simultaneously feel and express more positive mood (Niven et al., 2012). For instance, an instructor might smile when trying to improve a student's mood through praise. However, the instructor's expression of positive mood may also influence the student's mood through a process known as primitive emotional contagion. Primitive emotional contagion occurs when a person's affective experiences are expressed (e.g., via smiling) and unconsciously mimicked by others, with the physiological and inferential feedback from the mimicked behaviour causing others to feel the affect associated with that behaviour (Hatfield, Cacioppo, \& Rapson, 1994). Emotional contagion has been observed to occur from leaders to followers and from employees to customers (Johnson, 2008; Pugh, 2001). The positive mood of the employee may therefore increase the positive mood of others, which may then in turn result in higher task performance. This implies that the purported effects of an employee's IAR on another's positive mood and task performance may actually be due to the employee's positive mood. However, our theoretical arguments suggest that the effects of employee IAR and positive mood will occur through separate processes such that, the effects of employee IAR on others' positive mood and task performance should occur in addition to those caused by the employee positive mood. Our fourth hypothesis is: 
Hypothesis 4: The effects of employee IAR on others' positive mood and task performance will occur in addition to the effects of employee positive mood on others' positive mood and task performance.

\section{Overview of Studies}

We test our hypotheses across two studies, each involving matched dyads that comprised one person in a supervisor or instructor role and one person in a student or learner role. The first sample was university academics and doctoral students, while the second was driving instructors and learner drivers. In both studies, we assessed the student or learner's perspective on their receipt of IAR and their positive mood, while task performance was rated by the supervisor or instructor.

\section{Study 1}

Study 1 tested Hypotheses 1-3 in a sample of university academics and doctoral students. A lagged dyadic survey design was used in which students responded to a survey about their academic supervisor's use of IAR toward them and their mood, and academic supervisors responded to a different survey, three months later, asking about their student's performance.

\section{Sample and Procedure}

Data were collected from 78 pairs of university academics and doctoral students in a British university. To obtain this sample we independently contacted both academic and student (where academics had multiple doctoral students, we randomly selected one student). The response rate was $80 \%$. The student was sent a link to an online survey and a code to enter so that responses could be matched. Three months later the supervisor was sent an email asking for a response to a performance measure to assess the named student. Of the academics, $80 \%$ were women and $80 \%$ were aged between 35 and 54 . Of the students, $50 \%$ 
were female, $78 \%$ were aged between 21 and 25, and $47 \%$ were in their first year, $37 \%$ were in their second year, while the remaining $14 \%$ were in the third year or above.

\section{Measures}

Supervisor IAR To assess supervisor IAR, we asked students to complete the six-item affect-improving IAR scale from Niven, Totterdell, Holman \& Stride (2011), specifically with relation to strategies observed from the supervisor toward them. The items capture the main ways in which IAR strategies can enhance others' positive mood, namely, cognitive appraisal (My supervisor gave me helpful advice to try to improve how I felt; My supervisor discussed my positive achievements to try to improve how I felt), attention deployment (My supervisor made me laugh to try to make me feel better); situation modification (My supervisor did something nice with me to make me feel better) and relational engagement (My supervisor spent time with me to help me feel better; My supervisor listened to my problems to try to improve how I felt). Items were rated on a five-point scale from 'Not at all' to 'A great deal' $(\alpha=.84)$ and students were asked to rate the extent to which their supervisor had used these strategies in the last few weeks. We asked for student perceptions of the instructor's use of interpersonal affect regulation strategies as such strategies may only have an effect when their use is perceived by the target (Niven et al., 2012). For brevity, we report the combined factor analysis of the interpersonal affect regulation and positive mood items in the Appendix, Table A1.

Student positive mood A six item measure of positive mood was used (Warr, 1990). Three items reflected high states of positive activation (enthusiasm, optimistic, cheerful) and three items reflected low states of positive activation (calm, relaxed, content). We used these six items because they are consistent with our theoretical model which suggests that the broadening effects of positive mood can occur at high or low levels of activation (Fredrickson \& Branigan, 2005). Students were asked to rate the extent to which they had felt 
these affective states in the previous few weeks using a five-point scale ('Never' to 'All of the time'). A factor analysis (that also included the interpersonal affect regulation items, see Appendix, Table A1) produced two mood-related factors, one with three items indicating high states of positive activation (enthusiasm, optimistic, cheerful) and one with two items indicating low states of positive activation (calm, relaxed); and the content item loaded equally well on both factors. Consistent with our theoretical model and conceptualisations of positive mood (Fredrickson \& Branigan, 2005, Warr, 1990), we created a composite six-item index of positive mood that captured high and low states of positive affect and present our results using this composite measure (Cronbach's alpha was .83).

Student task performance The supervisor was asked to rate the performance of the student on a scale of 1-10, with 10 indicating that the student is one of the best performing $\mathrm{PhD}$ students that they have known and 1 indicating that the student is one of the worst performing they have known.

Controls We used a binary measure of year of study (first year or not) to account for the possibility that supervisors might rate students in the early stages of their doctorate more or less favourably.

\section{Analysis}

Path analysis in Mplus 8 (Muthén, 2017) was used to test the study hypotheses. The main model included paths from the independent variable (supervisor IAR) to the mediator (student positive mood) and outcome (student task performance), from the mediator to the outcome, and from the control (year of study) to all of the main variables. To test for mediated effects, we followed the procedure set out by Rucker, Preacher, Tormala, and Petty (2011), who recommend that to demonstrate mediation it is sufficient to show that the indirect effect is significant and that it is not necessary to first demonstrate a relationship between the independent and dependent variable (Shrout \& Bolger, 2002). As the distribution 
of the indirect effect $a b$ is typically non-normal, its significance was calculated by using bootstrapping to obtain bias corrected $95 \%$ confidence intervals.

\section{Results}

The correlations between the main study variables are shown in Table 1 . The results of the path analysis support our hypotheses. Specifically, in the test of our main model (See Figure $2)$, the path from student positive mood to student task performance $(\mathrm{H} 1)$ is significant $(\beta=$ $.55, \mathrm{p}<.05)$, the path from supervisor IAR to student positive mood $(\mathrm{H} 2)$ is significant $(\beta=$ $.42, \mathrm{p}<.05)$, and the indirect effect from supervisor IAR to student task performance via student positive mood $(\mathrm{H} 3)$ is significant $(\beta=.24,95 \% \mathrm{CI} L L=.01, \mathrm{UL}=.54)$. The results also reveal a significant direct positive relationship between supervisor IAR and student task performance $(\beta=.44, \mathrm{p}<.05)^{2}$.

\section{Study 2}

Study 2 tests Hypotheses 1-4 and builds on the findings from Study 1 in four ways. First, by testing Hypotheses 1-3, Study 2 tests the replicability and generalizability of the model in a separate sample of driving instructors and their learner drivers. As with Study 1, a dyadic survey design was used, in which learner drivers reported their own mood and their instructors' use of IAR, while driving instructors assessed their own mood and their learner's performance. Second, by testing Hypothesis 4, Study 2 establishes whether the effects of employee IAR on others' positive mood and task performance are in addition to those that may occur a result of the employees' positive mood, and thereby examines whether employees shape others' positive mood and task performance through two simultaneous

\footnotetext{
${ }^{2}$ The results are almost identical using a three-item high activation measure of positive mood. The path from student highly activated positive mood to student task performance is significant $(\theta=.50, p<.05)$, the path from supervisor IAR to student highly activated positive mood is significant $(\theta=.42, p<.01)$, the indirect effect from supervisor IAR to student task performance via student highly activated positive mood is significant $(B=$ $.21,95 \% \mathrm{Cl} \mathrm{LL}=.01, \mathrm{UL}=.48)$, and there is a significant direct positive relationship between supervisor IAR and student task performance $(B=.45, p<.05)$. However, the results were slightly different when a three-item low activation measure of positive mood was used, as the path from low activation positive mood to student task performance was not significant $(B=.28, \mathrm{~ns}$.), whereas all other paths were significant.
} 
affect-related process, one related to interpersonal affect regulation and one related to emotional contagion. Third, by controlling for the potentially confounding effects of the instructor's positive mood, Study 2 accounts for any potential affective bias in instructors' ratings of learner task performance. Fourth, Study 2 uses a multi-item measure of driving performance to provide a more robust measure of learner task performance than the singleitem measure used in Study 1.

\section{Sample and Procedure}

Data were collected from a sample of 100 pairs of driving instructors and learner drivers, all of whom were located in two large cities in Northern England. As driving instructors in the United Kingdom are self-employed, each instructor was contacted individually using names obtained from driving instructor associations and telephone directories. The response rate was $60 \%$. After agreeing to participate the driving instructor was sent a parcel that contained a survey to be completed by the driving instructor, a study information sheet and a reply envelope. The parcel also contained a survey, study information sheet and reply envelope to be given to one of the instructor's learner drivers. In order to avoid any selection biases (e.g., instructors choosing a favoured student), the driving instructor was asked to approach the third student on the next working day and to ask that student to complete the learner driver survey. The only selection criterion for the learner driver was that he or she must have had four or more lessons with the instructor, so as to rule out students who had limited interaction with the instructor. (A cut-off point of four lessons was decided upon in consultation with driving instructors and learner drivers who reported that a sufficient understanding of the other person's behaviour should have developed by this point). If the student refused to participate or did not meet the selection criteria, the instructor was asked to approach the next student. The instructor was asked to complete his or her survey making reference to the specific learner who completed the survey, and the instructor and student 
were asked to report the name of their student/instructor on the survey so that responses could be matched. Prepaid envelopes meant that the instructor and student were each able to post the survey directly to the research team.

Of the driving instructors, $30 \%$ were women, the average age was 49.23 years $(\mathrm{SD}=$ 10.10), and mean time in the job was 10.66 years $(S D=8.08)$. Of the learner drivers, $75 \%$ were female, the average age was 24.32 years $(\mathrm{SD}=10.04)$, and the average time spent in lessons with the driving instructor was 30.57 hours $(\mathrm{SD}=23.07)$. Fifty-three per cent of learner drivers had passed their theory test, which is a theoretical test about driving including questions about hazard perception and road signs. In XXX, the theory test must be taken before the practical driving test.

\section{Measures}

Driving instructor interpersonal affect regulation We adapted Niven et al.'s (2011) measure of affect-improving IAR strategies to ensure that the items were appropriate to the context (we did this by consulting with driving instructors) whilst also ensuring that the items covered the main types of IAR strategy. The resulting eight items reflect IAR strategies concerned with cognitive appraisal (My driving instructor gave me helpful advice to try to improve how I felt; My driving instructor discussed my positive achievements to try to improve how I felt; My driving instructor reminded me that I had done fine in similar situation before to try to improve how I felt), attentional deployment (My driving instructor made me laugh to try to make me feel better); situation modification (My driving instructor changed the nature of the lesson to try to improve how I felt, e.g., a different manoeuvre or route, My driving instructor took a short break from driving during the lesson to improve how I felt'), relational engagement (My driving instructor listened to my problems to try to improve how I felt), and, based on our consultation, an item on venting was included (My driving instructor allowed me to vent my emotions to try to improve how I felt) that Niven et 
al. (2009) identify as an affective engagement strategy. Learner drivers were asked to rate the extent to which the driving instructor had used each of the eight IAR strategies during their last four driving lessons. Items were rated on a five-point scale from 'Not at all' to 'A great deal'. Cronbach's alpha was .89 .

Learner driver positive mood A three-item measure of positive mood was used. From Warr's (1990) measure of psychological well-being we selected two items reflecting high (enthusiasm) and low (calmness) states of positive activation. We also added an item on pride, as this is a positive mood likely to be experienced when driving successfully. Learner drivers were asked to rate on a five-point scale ('Never' to 'All of the time') the extent to which they had felt this mood during lessons with the driving instructor. Cronbach's alpha was .79.

Learner driver task performance We created a measure of learner driver performance, as no suitable measure was available. In consultation with an Advanced Driving Instructor (i.e., a person who trains driving instructors) with over thirty years' experience, we developed seventeen items based on the main areas of driver competence assessed during the practical driving test in XX, e.g., awareness of road conditions, awareness of other vehicles, use of pedals, signalling, manoeuvring the car (DSA, 2007). Two other driving instructors were then asked to examine the items to further assess item face validity, which resulted in a few small changes to item wording. All three instructors agreed that the items covered the main areas of driver competence. A full list of the items used can be found in Appendix A. Each item asked the driving instructor to rate the ability of the learner driver using a seven-point scale from 'Very poor' to 'Very good'.

Exploratory factor analysis with oblimin rotation found four distinct factors with Eigen values greater than one. Two items had low factor loadings and were removed. A further factor analysis without these items found the same four factor structure (see Appendix A). 
The four factors accounted for $64.5 \%$ of the variance and are labelled: pedal use (e.g., the student is able to operate the accelerator smoothly, $\alpha=.84$ ); signalling and safe driving (e.g., the student makes good use of mirrors, the student drives adopts a safe driving speed, $\alpha=$ .80); traffic and signal awareness (e.g., the student demonstrates awareness of other vehicles, the student demonstrates awareness of traffic signals, $\alpha=.89$ ); and, manoeuvring (e.g., the student is able to drive safely at T-junctions, roundabouts and when merging, $\alpha=.83$ ). The four factors reflect the main areas of competence assessed in the practical driving test (control of vehicle and behaviour in traffic, DSA, 2009). This provides evidence for the content validity of the measure and indicates that the driving instructors in our sample were evaluating learner driver performance in a similar manner and in line with official expectations.

In our analysis we used a composite index of learner performance that combined all four factors to provide a broad assessment of learner performance and to increase model parsimony. The composite index had a Cronbach alpha of .92. To obtain further evidence for the validity of the composite measure we tested whether it was sensitive to actual differences in driving ability, as indicated by whether students had passed the mandatory theoretical driving test. A t-test revealed learner task performance to be significantly higher in those students who had passed the theory test $(\mathrm{M}=5.81, \mathrm{SD}=0.61)$ compared to those who had not passed the test $(\mathrm{M}=5.32, \mathrm{SD}=0.70, t=3.65, p<.01)$, thereby indicating that the composite measure is sensitive to actual differences in task performance.

Instructor positive mood Driving instructors were asked to assess their positive mood using the same three items that were used for the learner positive mood scale, i.e., enthusiasm, calmness and pride. Items were rated on a five point scale ('Never' to 'All of the time'). Cronbach's alpha was .74. 
Controls To account for differences in instructor skill, which might influence a learner driver's performance and affective experiences, we asked instructors to report their years of instructor experience.

\section{Analysis}

The analytical procedure tested the same mediational model as in Study 1 but had the following differences: paths from instructor mood to learner mood and learner performance; a correlation between instructor interpersonal affect regulation and instructor positive mood; and paths from driving instructor experience to the main study variables.

\section{Results}

The correlations between the Study 2 variables are shown in Table 2. The results of the path analysis (see Figure 3) support our hypotheses. Specifically, the path from learner driver positive mood to learner task performance $(\mathrm{H} 1)$ is significant $(\beta=.20, p<.05)$, the path from driving instructor IAR to learner driver positive mood $(\mathrm{H} 2)$ is significant $(\beta=.32, p<.01)$, and the indirect effect from instructor IAR to learner task performance via learner positive $\operatorname{mood}(\mathrm{H} 3)$ is significant $(\beta=.06,95 \% \mathrm{CI} L L=.01, \mathrm{UL}=.18)$. Hypothesis 4 is also confirmed, as the paths from instructor IAR to learner driver positive mood and task performance are significant when the paths from driving instructor positive mood on learner positive mood $(\beta=.23, p<.01)$ and learner driver task performance $(\beta=.19, p<.05)$ are included in the model. Furthermore, our analysis revealed that the indirect effect from instructor positive mood to learner task performance via learner positive mood is significant $(\beta=.05,95 \% \mathrm{CI} \mathrm{LL}=.01, \mathrm{UL}=.15)$. In addition, when instructor positive mood is removed from the aforementioned model, the paths from learner driver positive mood to learner task performance $(\beta=.24, \mathrm{p}<.05)$ and driving instructor IAR to learner driver positive mood 
remain significant $(\beta=.31, \mathrm{p}<.01)$, as does the indirect effect from instructor IAR to learner task performance via learner positive $\operatorname{mood}(\beta=.07,95 \% \mathrm{CI} L L=.01, \mathrm{UL}=.20){ }^{3}$

\section{Discussion}

Interpersonal affect regulation (IAR) is used within a range of organizational relationships and has previously been shown to influence the quality of those relationships and each party's well-being (Little et al., 2012; Martinez-Íñigo et al., 2013; Niven et al., 2012). The present research makes a key contribution to our understanding of IAR by establishing that an employee's use of affect-improving IAR towards another person is positively related with the other person's task performance. Specifically, across two studies, we find support for a model in which employee IAR is indirectly related to the task performance of another person (i.e., student, learner) via the other's positive mood. This evidence supported our model which theorised that receipt of IAR is associated with positive mood because IAR helps people to reappraise events, divert attention away from aversive stimuli or events, modify the situation to change its affective impact, and because it communicates interpersonal caring (Niven et al., 2012). In turn, and in line with Fredrickson's (2001) broaden-and-build theory, our model proposed that positive mood would enhance task performance by broadening behavioural and attentional repertoires and by facilitating integration of knowledge. A further important contribution is to show that, even though employee IAR and employee positive mood may co-occur, the relationship between employee IAR and another's positive mood and task performance occur alongside the relationship between employee positive mood and the positive mood of others. In particular, Study 2 demonstrated that the relationship of driving instructor IAR on learner driver mood and performance held over and above the relationship

\footnotetext{
${ }^{3}$ We also tested whether emotional intelligence moderated the effects of IAR on positive mood, and whether negative affect mediated the relationship between IAR and performance but found no significant effects. We also tested whether affect-worsening interpersonal affect regulation strategies were related to performance via positive mood but found no relationship between affect-worsening interpersonal affect regulation strategies and positive mood. Full results and information on measures used available on request.
} 
of instructor positive mood and learner driver positive mood. This suggests employees may shape the mood and performance of others through two simultaneous affect-related process, one related to interpersonal affect regulation and one related to emotional contagion (Pugh, 2001; Tsai et al., 2007). Our study therefore offers a more integrated account of the affectrelated processes through which employees shape the mood and task performance of others.

By showing that employee interpersonal affect regulation is related to the positive mood and task performance of others, our results have clear relevance to a range of occupational roles and types of relationship within organisations. For example, our findings are relevant to numerous occupational roles (e.g., teachers, lecturers, carers, health workers, trainers) in which a core objective is to develop the skills and performance of clients and customers; and they are relevant to those types of relationship within organisations in which the development of others is central, such as mentoring and coaching relationships. Furthermore, while our study did not focus on certain types of role or relationship, such as leaders and leaderfollower relationships, it seems reasonable to assume that similar IAR mechanisms will occur in these types of role and relationship (Little et al., 2016). Thus, our findings suggest that enhancing others' positive mood through the use of IAR strategies is an important way of improving the performance of others across a range of occupational roles and types of relationship. Simple behaviours like praising people's achievements, making them laugh, and listening to their concerns may therefore be just as important for people in these roles as guiding others through the technical aspects of their tasks. A practical implication of this is that training could be developed that seeks to enhance employee's use of a wide range of IAR strategies. Furthermore, IAR training interventions could focus on dyads of actors (e.g., leaders, instructors) and targets (e.g., team members, students) in which both parties could be trained to use and recognise the use of IAR, thereby enhancing the skills, performance, relationships and well-being of both parties, and open up new opportunities for the study of 
the coregulation of affect in organisational relationships, i.e., the bidirectional linkage of affective behaviours that contributes to affective experience of both partners (Butler $\&$ Randall, 2013).

While our results provide support for an affective mechanism linking employee IAR and other's task performance, other types of non-affective mechanisms may also be involved. For example, a cognitive mechanism featuring in theories of interpersonal behaviour (Horowitz et al., 2006; Sadler, Edier \& Woody, 2006) suggests that observers make cognitive inferences about the meaning of others' behaviour (e.g., IAR) and use these inferences to guide their own behaviours. Such a mechanism may explain why, in Study 1, we found a direct relationship between academic supervisors' IAR and student performance (when the indirect effects via students' mood were accounted for). Doctoral students may have inferred a concern for their development from their supervisors' attempts to improve their mood, which may have caused a desire to put more effort into their task performance due to reciprocity norms of social exchange (Cropanzano \& Mitchell, 2005). However, the direct effect of IAR on performance was not evident in Study 2 and this divergence in findings might be due to a crucial difference between the samples studied: while driving instructors (Study 2) are directly paid by their learners, doctoral supervisors (Study 1) are not. The paid nature of services in driving instruction may negate the reciprocity norms of social exchange, because people feel less obliged to reciprocate kindness if they believe that others' actions are simply part of the job (Belmi \& Pfeffer, 2015). In any case, the significance of the indirect effects via learners' mood in both studies clearly implicates positive mood as a core pathway through which supervisors' and instructors' IAR influences students' and learners' task performance.

Although there are strengths in our study design (e.g., the use of multi-source data), as with any research there are also limitations. One limitation is the cross-sectional nature of our data. In Study 1, our independent variable (IAR) and mediator (mood) were measured 
concurrently, while in Study 2 both these variables and the outcome (performance) were measured at the same time point. Nevertheless, there are strong theoretical reasons to anticipate effects in our interpreted direction, and it is not so clear why the reverse direction of causality would be expected. For example, there is no obvious reason why positive mood in a learner would lead to an instructor using more IAR to improve the learner's mood (rather, in this direction of causality, a negative relationship might be expected, whereby less positive mood would lead to greater use of IAR). The lagged measurement of the outcome variable in Study 1 provides further confidence in our interpretation of the findings but future research should test the relationships we have observed using an experimental design in order to overcome concerns about causality.

Further limitations concern the measures used. IAR and positive mood were both selfreport measures such that the relationships between them may have been inflated by common method variance. In addition, the single-item indicator of task performance in Study 1 may not have fully captured the range and variation learner performance, although this was rectified in Study 2 through the use of a multi-item indicator. There was also some variation in the use of the IAR measure over the two studies, primarily to ensure that the items in the Study 2 measure were appropriate to the context. But as the items in both studies reflected similar types of IAR strategy, such differences are unlikely to affect the comparability of study findings. Another issue concerning the measures of IAR was that we were unable to test the relative effectiveness of specific types of IAR strategy. For example, based on Gross' (1998) model of emotion regulation, Little et al. (2012) distinguish antecedent-focused IAR strategies, that seek to improve how others feel, from response-focused IAR strategies, that seek to alter others' expressions of positive affect. Antecedent-focused strategies were further categorised by whether they involve situation modification, cognitive change or attentional deployment. In a later study, Little and colleagues found differential relationships 
between IAR and customer expressions of positive and negative emotions in short one-off calls (Little, Kluemper, Nelson \& Ward, 2013). For example, customer expressions of positive emotion were positive related to situational modification, whereas customer expressions of negative emotion were negatively related to situational modification and cognitive change but positively related to attentional deployment and response-focused strategies. This suggests that antecedent-focused IAR strategies might vary in their impact on others' moods, particularly when compared to response-focused IAR strategies, such that future studies could seek to identify those IAR strategies that are most effective at improving the mood and task performance of others. An additional limitation is that our studies were conducted in two occupational contexts. Although these dyadic contexts made it easier to isolate and attribute the effects of an actor's IAR on the target's task performance (as the task performance of the learner depends heavily on instructor behaviour), it is important to replicate the findings in other occupational contexts and populations, such as those in which IAR may come from many sources and may not be used with an explicit coaching motive, e.g., between team members or between leaders and followers.

Finally, future research could build on our basic core model by incorporating other ways in which supervisors and instructors seek to improve task performance, such as goal setting, (Bindl, Parker, Totterdell, \& Hagger-Johnson, 2012; Keith \& Frese, 2005). Furthermore, alternative IAR mechanisms should be examined, such as the cognitive mechanisms highlighted earlier, as should different forms of IAR and the role of IAR in shaping negative mood or discrete emotions such as anger or shame. For example, research could test whether affect-worsening IAR strategies influence others' task performance via discrete negative emotions, such as might occur when an instructor tries to make a potentially dangerous learner driver feel ashamed of their unsafe driving by reminding the driver of how this might affect others. In addition, it is crucial that the boundary conditions of our basic model are 
established, as the effects of IAR could depend on the type of relationship between the regulator and target, or on individual differences such as the political or interpersonal skill of the regulator. In summary, while our study points to the important role that interpersonal affect regulation plays in shaping the mood and task performance of others, there is a clear need to understand how this process occurs in relation to other influences on mood and task performance, and how it is shaped by individual characteristics and the social context.

\section{References}

Belmi, P., \& Pfeffer, J. (2015). How “organization” can weaken the norm of reciprocity: The effects of attributions for favors and a calculative mindset. Academy of Management Discoveries, 1, 36-57.

Bindl, U. K., Parker, S. K., Totterdell, P., \& Hagger-Johnson, G. (2012). Fuel of the selfstarter: How mood relates to proactive goal regulation. Journal of Applied Psychology, 97, 134.

Butler, E. A., \& Randall, A. K. (2013). Emotional coregulation in close relationships. Emotion Review, 5, 202-210.

Carver, C. S., \& Scheier, M. F. (1990). Origins and functions of positive and negative affect: A control-process view. Psychological Review, 97, 19-35.

Christian, M. S., Garza, A. S., \& Slaughter, J. E. (2011). Work engagement: A quantitative review and test of its relations with task and contextual performance. Personnel Psychology, 64, 89-136.

Colquitt, J. A., LePine, J. A., \& Noe, R. A. (2000). Toward an integrative theory of training motivation: a meta-analytic path analysis of 20 years of research. Journal of Applied Psychology, 85, 678-707.

Cropanzano, R., \& Mitchell, M. S. (2005). Social exchange theory: An interdisciplinary review. Journal of Management, 31, 874-900. 
Derryberry, D., \& Tucker, D. M. (1994). Motivating the focus of attention. In P. Niedenthal and S. Kitayama (Eds). The heart's eye: Emotional influences in perception and attention. (pp. 167-196). San Diego, CA, US: Academic Press.

Driving Standards Agency (2007). Driving test report. London, HMSO.

Driving Standards Agency (2009). The Official DSA guide to learning to drive. London, HMSO.

Erez, A., \& Isen, A. M. (2002). The influence of positive affect on the components of expectancy motivation. Journal of Applied psychology, 87, 1055-1067.

Ferris, G. R., Liden, R. C., Munyon, T. P., Summers, J. K., Basik, K. J., \& Buckley, M. R. (2009). Relationships at work: Toward a multidimensional conceptualization of dyadic work relationships. Journal of Management, 35, 1379-1403.

Fredrickson, B.L. (2001). The role of positive emotions in positive psychology: The broadenand-build theory of positive emotions. American Psychologist, 56, 218-226.

Fredrickson, B. L., \& Branigan, C. (2005). Positive emotions broaden the scope of attention and thought-action repertoires. Cognition \& Emotion, 19, 313-332.

Fredrickson, B. L., \& Joiner, T. (2002). Positive emotions trigger upward spirals toward emotional well-being. Psychological Science, 13, 172-175.

Friedman, R. S., \& Förster, J. (2010). Implicit affective cues and attentional tuning: an integrative review. Psychological Bulletin, 136, 875-893.

Griffin, M. A., Neal, A., \& Parker, S. K. (2007). A new model of work role performance: Positive behavior in uncertain and interdependent contexts. Academy of Management Journal, 50, 327-347.

Gross, J. J. (1998). The emerging field of emotion regulation: An integrative review. Review of General Psychology, 2, 271-299. 
Hatfield, E., Cacioppo, J., \& Rapson, R. L. (1994). Emotional contagion. New York, NY: Cambridge University Press.

Hochschild, A. R. (1983). The managed heart: Commercialization of human feeling. Berkeley, CA: University of California Press.

Horowitz, L. M., Wilson, K. R., Turan, B., Zolotsev, P., Constantino, M. J., \& Henderson, L. (2006). How interpersonal motives clarify the meaning of interpersonal behavior: A revised circumplex model. Personality and Social Psychology Review, 10, 67-86.

Isen, A. M. (2008). Some ways in which positive affect influences decision making and problem solving. In M. Lewis, J. M. Haviland Jones, \& L Feldman Barrett (Eds.) Handbook of Emotions (pp. 548-573). New York, Guilford Press.

Isen, A. M., Daubman, K. A., \& Nowicki, G. P. (1987). Positive affect facilitates creative problem solving. Journal of Personality and Social Psychology, 52, 1122-1131.

Johnson, S. K. (2008). I second that emotion: Effects of emotional contagion and affect at work on leader and follower outcomes. The Leadership Quarterly, 19, 1-19.

Keith, N., \& Frese, M. (2005). Self-regulation in error management training: emotion control and metacognition as mediators of performance effects. Journal of Applied Psychology, 90, 677-691.

Konradt, U., Filip, R., \& Hoffmann, S. (2003). Flow experience and positive affect during hypermedia learning. British Journal of Educational Technology, 34, 309-327.

Little, L. M., Gooty, J., \& Williams, M. (2016). The role of leader emotion management in leader-member exchange and follower outcomes. The Leadership Quarterly, 27, 85-97.

Little, L. M., Kluemper, D., Nelson, D. L., \& Gooty, J. (2012). Development and validation of the interpersonal emotion management scale. Journal of Occupational and Organizational Psychology, 85, 407-420. 
Little, L. M., Kluemper, D., Nelson, D. L., \& Ward, A. (2013). More than happy to help? Customer-focused emotion management strategies. Personnel Psychology, 66, 261-286. Locke, E. A., \& Latham, G. P. (1990). A theory of goal setting and task performance. Englewood Cliffs, NJ: Prentice-Hall.

Lyubomirsky, S., King, L., \& Diener, E. (2005). The benefits of frequent positive affect: does happiness lead to success? Psychological Bulletin, 131, 803-855.

Martínez-Íñigo, D., Poerio, G. L., \& Totterdell, P. (2013). The association between controlled interpersonal affect regulation and resource depletion. Applied Psychology: Health and Well-Being, 5, 248-269.

Martocchio, J. J. (1994). Effects of conceptions of ability on anxiety, self-efficacy, and learning in training. Journal of Applied Psychology, 79, 819-825.

Muthén, L. K. (2017). Mplus: Statistical Analysis with Latent Variables (Version 8)[Computer software].

Mikulincer, M., \& Shaver, P. R. (2009). An attachment and behavioural systems perspective on social support. Journal of Social and Personal Relationships, 26, 7-19.

Miner, A. G., \& Glomb, T. M. (2010). State mood, task performance, and behaviour at work: A within-persons approach. Organizational Behaviour and Human Decision Processes, $112,43-57$.

Niven, K. (2016). Why do people engage in interpersonal emotion regulation at work? Organizational Psychology Review, 6, 305-323.

Niven, K. (2017). The four key characteristics of interpersonal emotion regulation. Current Opinion in Psychology, 17, 89-93.

Niven, K., Holman. D., \& Totterdell, P. (2012). How to win friendship and trust by influencing people's feelings: An investigation of interpersonal affect regulation and the quality of relationships. Human Relations, 65, 777-805. 
Niven, K., Totterdell, P., \& Holman, D. (2009). A Classification of Controlled Interpersonal Affect Regulation Strategies. Emotion, 9, 498-509.

Niven, K., Totterdell, P., \& Holman, D. (2007). Changing moods and influencing people: the use and effects of emotional influence behaviours at HMP Grendon. Prison Service Journal, 173, 39-45.

Niven, K., Totterdell, P., Holman, D., \& Headley, T. (2012). Does regulating others' feelings influence people's own affective well-being? The Journal of Social Psychology, 152, 246-260.

Niven, K., Totterdell, P., Stride, C. B., \& Holman, D. (2011). Emotion Regulation of Others and Self (EROS): The development and validation of a new individual difference measure. Current Psychology, 30, 53-73.

Nummenmaa, L., \& Niemi, P. (2004). Inducing affective states with success-failure manipulations: a meta-analysis. Emotion, 4, 207-214.

Parkinson, B., Fischer, A. H., \& Manstead, A. S. R. (2005). Emotions in Social relations: Cultural group and interpersonal processes, New York, Psychology Press.

Pugh, S. D. (2001). Service with a smile: Emotional contagion in the service encounter. Academy of Management Journal, 44, 1018-1027.

Richards, D. A., \& Schat, A. C. (2011). Attachment at (not to) work: applying attachment theory to explain individual behaviour in organizations. Journal of Applied Psychology, 96, 169-182.

Rothbard, N. P., \& Wilk, S. L. (2011). Waking up on the right or wrong side of the bed: Start-of-workday mood, work events, employee affect, and performance. Academy of Management Journal, 54, 959-980. 
Rucker, D. D., Preacher, K. J., Tormala, Z. L., \& Petty, R. E. (2011). Mediation analysis in social psychology: Current practices and new recommendations. Social and Personality Psychology Compass, 5/6, 359-371.

Russell, J. A. (2003). Core affect and the psychological construction of emotion. Psychological Review, 110, 145-172.

Russell, J. A., \& Barrett, L. F. (1999). Core affect, prototypical emotional episodes, and other things called emotion: dissecting the elephant. Journal of Personality and Social Psychology, 76, 805-819.

Sadler, P., Ethier, N. \& Woody, E. (2011). Interpersonal complimentarity. In Horowitz L.M. and Strack S. (Eds). Handbook of interpersonal psychology: Theory, research, assessment and therapeutic interventions. (pp 123-142). Hoboken, NJ: Wiley.

Seo, M. G., Barrett, L. F., \& Bartunek, J. M. (2004). The role of affective experience in work motivation. Academy of Management Review, 29, 423-439.

Shrout, P. E., \& Bolger, N. (2002). Mediation in experimental and non-experimental studies: New procedures and recommendations. Psychological Methods, 7, 422-445.

Sutton, R. E., Mudrey-Camino, R., \& Knight, C. C. (2009). Teachers' emotion regulation and classroom management. Theory into Practice, 48, 130-137.

Totterdell, P. (1999). Mood score: Mood and performance in professional cricketers. British Journal of Psychology, 90, 317-332.

Totterdell, P., \& Holman, D. (2003). Emotion regulation in customer service roles: testing a model of emotional labor. Journal of Occupational Health Psychology, 8, 55-73.

Towler, A., Arman, G., Quesnell, T., \& Hoffman, L. (2014). How charismatic trainers inspire others to learn through positive affectivity. Computers in Human Behavior, 32, 221228. 
Tsai, W.C., Chen C. C. \& Lui, H. L. (2007). Test of a model linking employee positive moods and task performance. Journal of Applied Psychology, 92, 1570-1583.

Wadlinger, H. A., \& Isaacowitz, D. M. (2006). Positive mood broadens visual attention to positive stimuli. Motivation and Emotion, 30, 87-99.

Warr, P. (1990). The measurement of well-being and other aspects of mental health. Journal of Occupational Psychology, 63, 193-210.

Warr, P., \& Downing, J. (2000). Learning strategies, learning anxiety and knowledge acquisition. British Journal of Psychology, 91, 311-333.

Weiss, H. M., \& Cropanzano, R. (1996). Affective events theory: A theoretical discussion of the structure, causes and consequences of affective experiences at work. In B. M. Staw \& L. L. Cummings (Eds.), Research in organizational behavior: An annual series of analytical essays and critical reviews, Vol. 18, pp. 1-74). US: Elsevier Science/JAI Press.

Westermann, R., Stahl, G., \& Hesse, F. (1996). Relative effectiveness and validity of mood induction procedures: analysis. European Journal of Social Psychology, 26, 557-580. 
Table 1. Study 1 Variables: Means, Standard Deviations and Correlations ( $\mathrm{N}=78$ dyads)

\begin{tabular}{|c|c|c|c|c|c|c|}
\hline & Means & SD & 1 & 2 & 3 & 4 \\
\hline \multicolumn{7}{|l|}{ Supervisor-rated variables } \\
\hline 1. Student task performance & 7.26 & 1.65 & - & & & \\
\hline \multicolumn{7}{|l|}{ Student-rated variables } \\
\hline 2. Supervisor interpersonal affect & 2.93 & .79 & $.30 * *$ & - & & \\
\hline \multicolumn{7}{|l|}{ regulation } \\
\hline 3. Student positive affect (6-item) & 2.93 & .66 & $.31 * *$ & $.52 * *$ & - & \\
\hline 4. Year 1 of study & .47 & .50 & -.07 & $.23^{*}$ & .04 & - \\
\hline
\end{tabular}


Table 2. Study 2 Variables: Means, Standard Deviations and Correlations ( $N=100$ dyads)

\begin{tabular}{lcccccc}
\hline & Means & SD & $\mathbf{1}$ & $\mathbf{2}$ & $\mathbf{3}$ & $\mathbf{4}$ \\
\hline Instructor-rated variables & & & & & \\
1. Learner task performance & 5.62 & .69 & - & & \\
2. Instructor positive mood & 4.07 & .70 & $.26^{* *}$ & - & \\
3. Years of experience & 10.60 & 8.29 & $-.21^{*}$ & -.10 & - \\
Learner-rated variables & & & & & \\
4. Instructor interpersonal affect regulation & 3.63 & .78 & .07 & .00 & $-.21^{*}$ & - \\
5. Learner positive mood & 3.61 & .76 & $.23^{*}$ & $.20^{*}$ & .07 & $.29 * *$ \\
\hline
\end{tabular}


Figure 1. Model of interpersonal affect regulation, positive mood and performance.

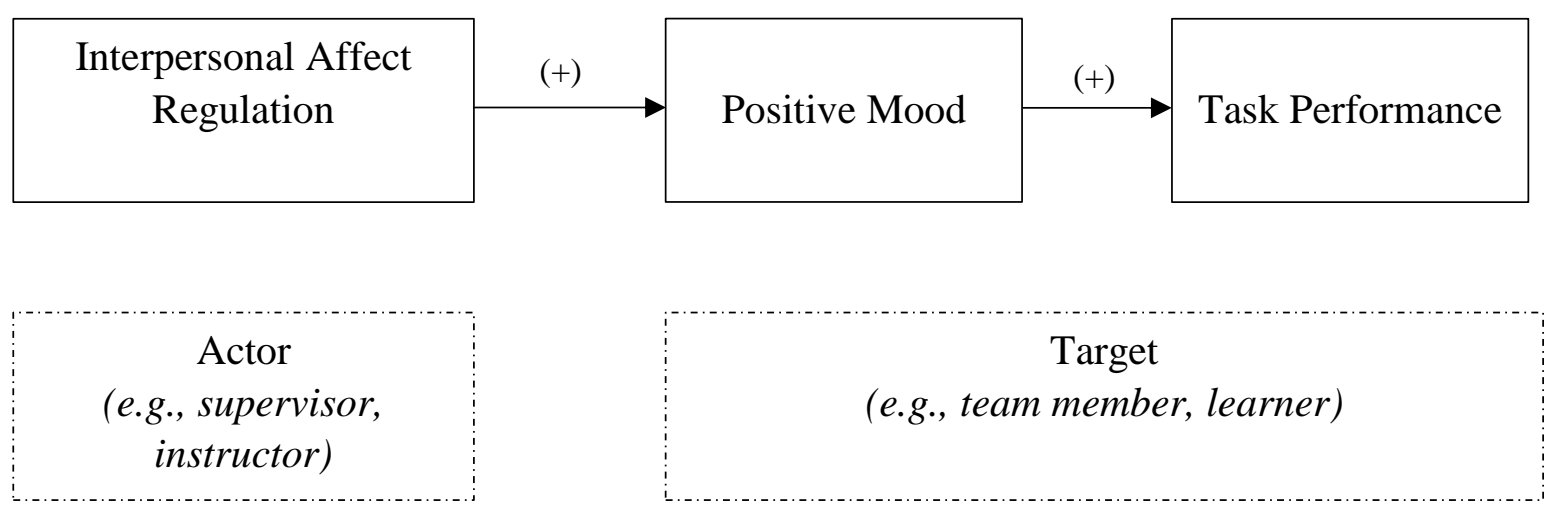


Figure 2. Effects of doctoral supervisor IAR on doctoral student performance in Study $1(\mathrm{~N}=$ 78 dyads)

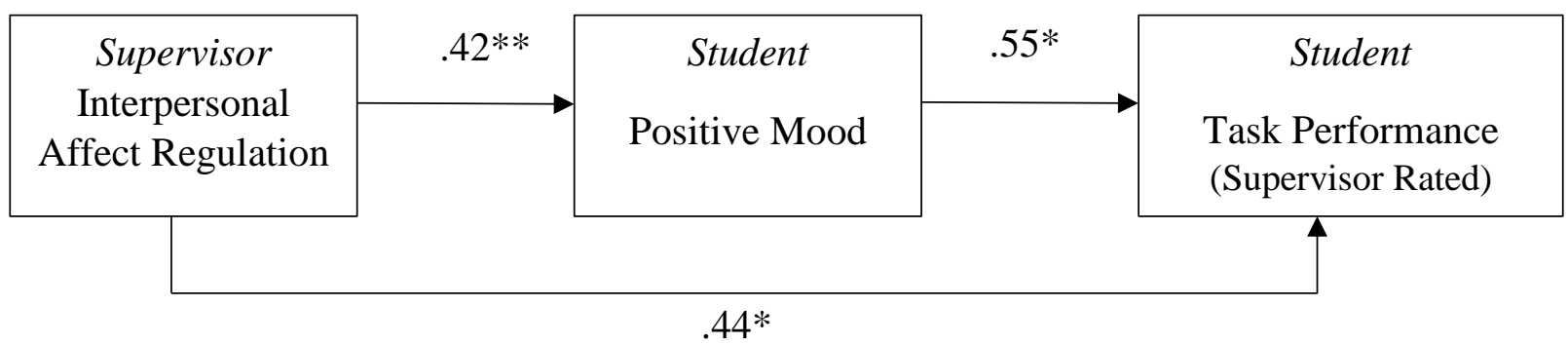

Note: $*=p<.05, * *=p<.01$, Controls not shown: study year and interpersonal affect regulation $(\beta=$ $\left..37^{*}\right)$, positive $\operatorname{mood}(\beta=-.07, n s)$ and task performance $(\beta=-.38, \mathrm{~ns}$.$) .$ 
Figure 3. Effects of driving instructor IAR on learner driver performance in Study $2(\mathrm{~N}=100$ dyads)

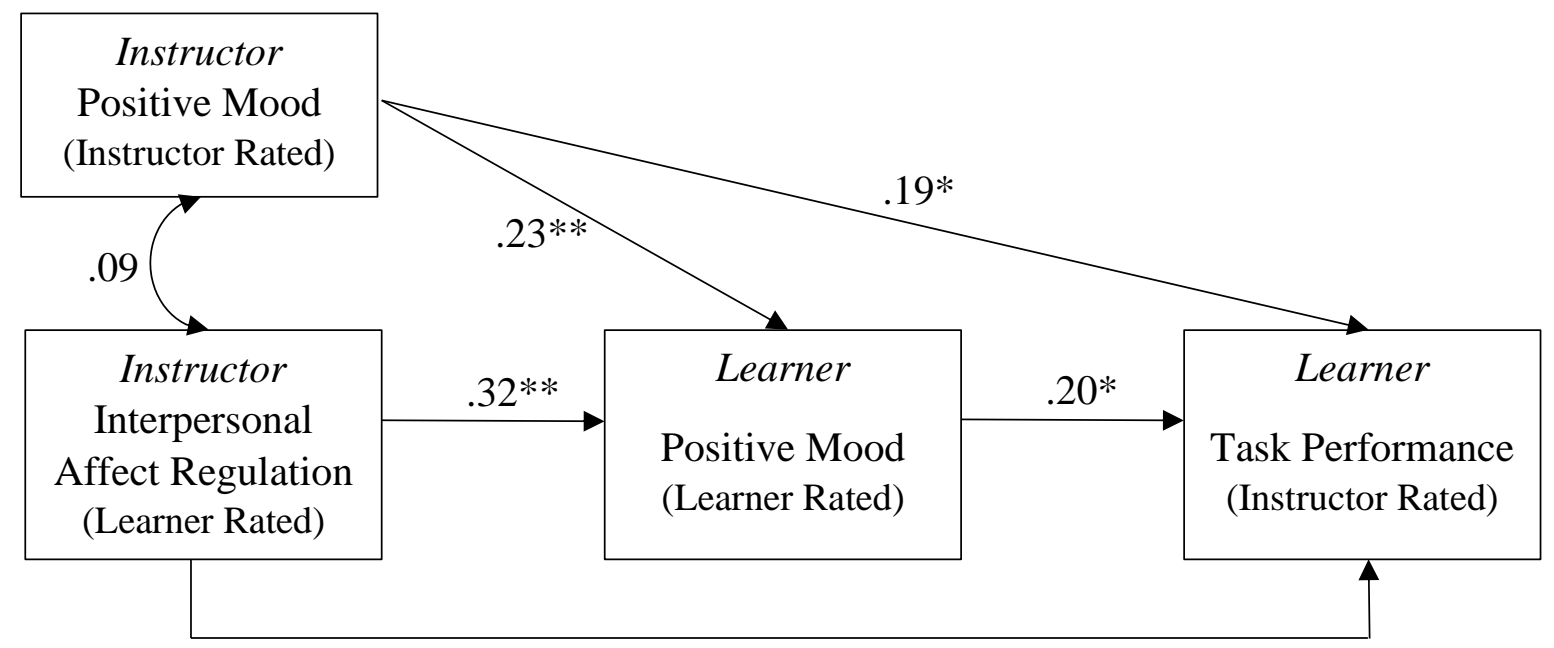

.05

Note: $*=p<.05, * *=p<.01$. Controls not shown between driving instructor experience and instructor IAR $(\beta=-.16, p<.05)$, instructor positive $\operatorname{mood}(\beta=-.06, \underline{\mathrm{ns}})$, learner positive $\operatorname{mood}(\beta=.12, p<.05)$, and learner task performance $(\beta=-.15, p<.05)$. 


\section{Appendix. Factor Analysis Results}

Table A1. Study 1: Doctoral Student Measures

\begin{tabular}{lccc}
\hline & $\mathbf{1}$ & $\mathbf{2}$ & $\mathbf{3}$ \\
\hline 1. Interpersonal Affect Regulation & & & \\
My supervisor gave me helpful advice. & & & -.37 \\
My supervisor did something nice with me. & $\mathbf{. 6 7}$ & -.01 & .05 \\
My supervisor discussed my positive & $\mathbf{. 5 7}$ & .07 & -.15 \\
characteristics with me. & & & \\
My supervisor made me laugh. & $\mathbf{. 7 0}$ & -.03 & -.05 \\
My supervisor listened to my problems. & $\mathbf{. 8 2}$ & .04 & .08 \\
My supervisor spent time with me. & $\mathbf{. 6 8}$ & -.13 & .10 \\
2. Positive Affect & & & \\
Calm & .04 & -.75 & .02 \\
Relaxed & -.05 & -.94 & -.06 \\
Content & .31 & -.35 & -.35 \\
Optimistic & -.01 & -.15 & $\mathbf{- . 7 0}$ \\
Enthusiastic & -.04 & .12 & $\mathbf{- . 9 0}$ \\
Cheerful & .13 & -.21 & $\mathbf{- . 5 8}$ \\
\hline Note. ${ }^{1}$ Adapted from Niven et al. (2011) & & &
\end{tabular}

Note: ${ }^{1}$ Adapted from Niven et al. (2011). 
Table A2. Study 2: Learner Driver Measures

\begin{tabular}{lcc}
\hline & $\mathbf{1}$ & $\mathbf{2}$ \\
\hline $\begin{array}{l}\text { 1. Interpersonal Affect Regulation } \\
\text { My driving instructor made me laugh to try to }\end{array}$ & $\mathbf{. 7 2}$ & -.04 \\
make me feel better & & \\
$\begin{array}{l}\text { My driving instructor discussed my positive } \\
\text { achievements to try to improve how I felt }\end{array}$ & $\mathbf{4 6}$ & .24 \\
$\begin{array}{l}\text { My driving instructor reminded me that I had } \\
\text { done fine in similar situation before to try to }\end{array}$ & $\mathbf{. 5 3}$ & .30 \\
$\begin{array}{l}\text { improve how I felt } \\
\text { My driving instructor gave me helpful advice } \\
\text { to try to improve how I felt }\end{array}$ & $\mathbf{. 7 3}$ & .04 \\
$\begin{array}{l}\text { My driving instructor listened to my } \\
\text { problems to try to improve how I felt }\end{array}$ & $\mathbf{. 8 5}$ & -.07 \\
$\begin{array}{l}\text { My driving instructor took a short break from } \\
\text { driving during the lesson to improve how I } \\
\text { felt }\end{array}$ & $\mathbf{. 5 6}$ & $\mathbf{- . 1 1}$ \\
$\begin{array}{l}\text { My driving instructor allowed me to vent my } \\
\text { emotions to try to improve how I felt }\end{array}$ & $\mathbf{. 7 2}$ & .11 \\
$\begin{array}{l}\text { My driving instructor changed the nature of } \\
\text { the lesson to try to improve how I felt }\end{array}$ & $\mathbf{. 5 2}$ & -.05 \\
$\begin{array}{l}\text { Student Positive Affect } \\
\text { Enthusiasm }\end{array}$ & & \\
$\begin{array}{l}\text { Calm } \\
\text { Pride }\end{array}$ & .03 & $\mathbf{- . 7 2}$ \\
\hline
\end{tabular}

Note: ${ }^{1}$ Adapted from Niven et al. (2011). 
Table A3. Study 2: Driving Instructor Measures

\begin{tabular}{|c|c|c|c|c|c|}
\hline & 1 & 2 & 3 & 4 & 5 \\
\hline \multicolumn{6}{|l|}{ 1. Learner Driver Performance } \\
\hline \multicolumn{6}{|l|}{ a. Traffic and Signal Awareness } \\
\hline $\begin{array}{l}\text { Demonstrates an awareness of traffic } \\
\text { symbols }\end{array}$ & .59 & -.08 & .21 & .19 & .08 \\
\hline $\begin{array}{l}\text { Demonstrates an awareness of other } \\
\text { vehicles }\end{array}$ & .71 & -.13 & .08 & .13 & .11 \\
\hline $\begin{array}{l}\text { Demonstrates an awareness of } \\
\text { pedestrians/cyclists }\end{array}$ & .65 & -.07 & .15 & .19 & .18 \\
\hline \multicolumn{6}{|l|}{ b. Pedal Use } \\
\hline Is able to operate accelerator correctly & -.14 & -.70 & .04 & -.07 & .08 \\
\hline Is able to operate clutch smoothly & -.01 & -.96 & -.09 & .12 & -.05 \\
\hline Is able to change gears correctly & .08 & -.68 & .21 & -.06 & -.03 \\
\hline \multicolumn{6}{|l|}{ c. Manoeuvring the car } \\
\hline $\begin{array}{l}\text { Is able to drive safely at } \mathrm{T} \text {-junctions, } \\
\text { roundabouts and when merging }\end{array}$ & -.08 & -.19 & .59 & .05 & .03 \\
\hline $\begin{array}{l}\text { Is able to stay within a lane, obeys road } \\
\text { markings, selects the correct lane and } \\
\text { changes lanes safely }\end{array}$ & -.04 & -.07 & .83 & -.06 & -.07 \\
\hline $\begin{array}{l}\text { Recognizes hazards and reacts } \\
\text { appropriately }\end{array}$ & -.03 & .06 & .91 & .01 & .07 \\
\hline $\begin{array}{l}\text { Is able to maintain car control in a confined } \\
\text { area and can judge distances from objects } \\
\text { accurately }\end{array}$ & .00 & -.06 & .66 & .17 & -.03 \\
\hline \multicolumn{6}{|l|}{ d. Signalling and Safe Driving } \\
\hline Makes good use of mirrors & -.07 & -.03 & -.09 & .77 & .01 \\
\hline Signals when necessary & -.03 & .04 & .21 & .59 & .07 \\
\hline $\begin{array}{l}\text { Adopts a safe road speed and observes } \\
\text { speed limits }\end{array}$ & -.16 & .00 & .00 & .66 & -.06 \\
\hline $\begin{array}{l}\text { Drives according to the road and weather } \\
\text { conditions }\end{array}$ & -.03 & .06 & .20 & .63 & -.05 \\
\hline $\begin{array}{l}\text { When moving off, he/she selects 'drive' } \\
\text { gear, looks over his/her shoulder and } \\
\text { comfortably moves the vehicle off }\end{array}$ & .27 & -.16 & .06 & .46 & .16 \\
\hline \multicolumn{6}{|l|}{ 2. Driving Instructor Positive Affect } \\
\hline Enthusiasm & .08 & .14 & .03 & -.05 & 1.05 \\
\hline Calm & -.03 & -.06 & .03 & .00 & .57 \\
\hline Proud & -.11 & -.05 & -.07 & .02 & .52 \\
\hline
\end{tabular}

Note: The four learner driver performance factors are all positively correlated with each other. 